\title{
Unió Valenciana (1982-2008). Una aproximación
}

\author{
Anselm Bodoque Arribas
}

Universitat de València

anselm.bodoque@uv.es

\section{Resumen}

Unió Valenciana (UV) es el único partido valenciano de ámbito no estatal que, desde la restauración democrática de 1977, ha estado representado, durante algunas legislaturas, tanto en las instituciones locales como en los parlamentos español y valenciano. En primer lugar, estudiamos las fracturas sociopolíticas que dan lugar al regionalismo anticatalanista valenciano contemporáneo y a su máximo exponente político: Unió Valenciana. Posteriormente, nos referimos a la historia de esta fuerza política. Finalmente, analizamos la importancia de UV dentro del sistema valenciano de partidos, la evolución de su apoyo electoral y de su capacidad de representación en los distintos ámbitos institucionales. Concluimos que el nacimiento, la evolución y la decadencia de UV han sido paralelos y han dependido de la fortaleza del principal partido de la derecha valenciana (AP/PP) en los últimos veinticinco años.

Palabras clave: partidos políticos, sistema de partidos, identidad colectiva, regionalismo, nacionalismo.

\section{Resum. Unió Valenciana (1982-2008). Una aproximació}

Unió Valenciana (UV) és l'únic partit valencià d'àmbit no estatal que, des de la restauració democràtica de 1977, ha estat representat, durant algunes legislatures, tant en les institucions locals com en els parlaments espanyol i valencià. En primer lloc, estudiem les fractures sociopolítiques que donen lloc al regionalisme anticatalanista valencià contemporani i al seu màxim exponent polític: Unió Valenciana. Posteriorment, ens referim a la història d'aquesta força política. Finalment, analitzem la importància d'UV dins del sistema valencià de partits, l'evolució del seu suport electoral i de la seua capacitat de representació en els distints àmbits institucionals. Concloem que el naixement, l'evolució i la decadència d'UV han estat paral.lels i han depès de la fortalesa del principal partit de la dreta valenciana (AP/PP) en els últims vint-i-cinc anys.

Paraules clau: partits polítics, sistema de partits, identitat col-lectiva, regionalisme, nacionalisme.

\section{Abstract. Unió Valenciana (1982-2008). An approximation}

Unió Valenciana (UV) is the only no state Valencian party that has been represented both in local institutions such as Spanish and Valencian parliaments, during some legislatures, 
since the restoration of democracy in Spain in 1977. First, we study the social cleavages that they are in the origin of contemporary anticatalan Valencian regionalism and its most important: Unió Valenciana. Later we refer to the history of this political force. Finally, we analyze the importance of UV within the Valencian system of parties, the evolution of its electoral support and its capacity for representation in the different institutions. We conclude is that the birth, evolution and decay of UV as party have been parallel and have depended on the strength of the main Valencian party of the right (AP/PP) in the last twenty-five years.

Key words: political parties, party system, collective identity, regionalism, nationalism.

\section{Sumario}

\section{Introducción}

2. Las fracturas políticas en torno a la identidad valenciana

3. Los discursos en torno a la identidad valenciana: el anticatalanista identitario

\section{Historia breve de Unió Valenciana}

5. Comportamiento electoral de UV en el sistema valenciano de partidos

\section{Introducción}

Este trabajo tiene como objetivo básico el conocimiento descriptivo de Unió Valenciana (UV), el único partido valenciano de ámbito no estatal (PANE) que, desde la restauración democrática de 1977, ha conseguido estar representado en algún momento de su historia, además de en las instituciones locales, en el Parlamento español y en el valenciano. Dividiremos nuestro trabajo en tres partes. En primer lugar, analizaremos las escisiones y las fracturas sociopolíticas que dan lugar al regionalismo anticatalanista valenciano contemporáneo y a su máximo exponente político, Unió Valenciana; en segundo lugar, presentaremos una historia sucinta de esta fuerza política, y, en tercer y último lugar, hablaremos de la importancia de UV y de los PANE valencianos dentro del sistema valenciano de partidos, la evolución de su apoyo electoral y de su capacidad de representación en los distintos ámbitos institucionales, para acabar señalando que algunos de los tópicos del discurso del regionalismo anticatalanista son difícilmente sostenibles si se contrastan con la realidad, ya que su evolución es pareja a la del centro-derecha valenciano en las últimas tres décadas.

Los partidos valencianos de ámbito no estatal son una realidad política poco conocida fuera (y dentro) de la Comunidad Valenciana y escasamente estudiada de manera específica. La poca atención que hasta ahora han merecido podría explicarse, además de por la condición subalterna de la política valenciana en el conjunto de España, por el hecho de que estamos refiriéndonos a formaciones que no han influido en la política española y que han tenido una importancia de segundo orden en la valenciana, a pesar de que UV llegara a formar parte del Gobierno Valenciano durante una legislatura. 


\section{Las fracturas políticas en torno a la identidad valenciana}

La principal fractura política valenciana está determinada por la dimensión tradicional derecha-izquierda, y es sobre este eje que se sitúan y se definen los principales partidos políticos de la Comunidad Valenciana. No obstante, hay un eje de fractura secundario, y de menor significación política, que tiene su origen en la identidad del pueblo valenciano, en la condición nacionalitària de los valencianos y su integración en España. El resto de posibles fracturas políticas (religión, ecología, diversidad étnica, etc.) no han tenido hasta el momento la menor importancia en términos sociales y electorales.

Será en torno a la fractura identitaria de base lingüística donde tendrán su razón de ser los partidos de ámbito no estatal, en una sociedad en donde las identidades predominantes tienden a ser mixtas y es muy superior la cifra de los que se consideran sólo o preferentemente españoles a la de los que se afirman solamente valencianos o más valencianos que españoles (ver tabla 1).

Sin embargo, mientras que, en otras comunidades políticas, la fractura identitaria está delimitada exclusivamente por el grado de identificación preferente con la propia comunidad o con España, en el caso valenciano, se ha producido una escisión polarizada en torno a los elementos básicos que definen la propia identidad, lo que daría lugar a un mapa de identidades más complejo. Y este hecho, que quizá sea la particularidad más destacable de la realidad política valenciana, ha dado lugar a concepciones del valencianismo político enfrentadas, a menudo de manera irreconciliable, tanto en la respuesta que daban al problema de la vinculación con España, como, sobre todo, en la misma definición de la identidad de los valencianos en aspectos centrales del discurso valencianista tales como la lengua, la historia, la cultura, los símbolos, el nombre del territorio y la pertenencia nacional (ver grafico 1).

Tabla 1. Identidad de los valencianos

\begin{tabular}{lcccccc}
\hline & $\begin{array}{c}\text { Octubre } \\
\text { de 1984 }\end{array}$ & $\begin{array}{c}\text { Noviembre } \\
\text { de 1992 }\end{array}$ & $\begin{array}{c}\text { Enero } \\
\text { de 2000 }\end{array}$ & $\begin{array}{c}\text { Febrero } \\
\text { de 2002 }\end{array}$ & $\begin{array}{c}\text { Abril } \\
\text { de 2004 }\end{array}$ & $\begin{array}{c}\text { Noviembre } \\
\text { de 2005 }\end{array}$ \\
\hline $\begin{array}{l}\text { Sólo español } \\
\text { Más español } \\
\text { que valenciano }\end{array}$ & 14,5 & 20,8 & 20,5 & 23,7 & 23,6 & 14,6 \\
$\begin{array}{l}\text { Tan español } \\
\text { como valenciano }\end{array}$ & 50,9 & 10,6 & 9,7 & 11,2 & 13,6 & 18,3 \\
\hline $\begin{array}{l}\text { Más valenciano } \\
\text { que español }\end{array}$ & 10,0 & 76,7 & 58,1 & 52,0 & 49,3 & 55,9 \\
\hline $\begin{array}{l}\text { Sólo valenciano } \\
\text { NS/NC }\end{array}$ & 0,7 & 1,1 & 1,9 & 2,6 & 2,4 & 1,5 \\
\hline
\end{tabular}

Fuente: CIS (Centro de Investigaciones Sociológicas); n. 1437, Barómetro de la Comunidad Valenciana, octubre de 1984; n. 2034, Opinión Pública y Cultura Política en las Comunidades Autónomas, noviembre de 1992; n. 2378, Situación Social y Política en la Comunidad Valenciana, enero de 2000; n. 2445, Estudio Sociológico de la Comunidad Valenciana, febrero de 2002; n. 2560, Estudio Sociológico de la Comunidad Valenciana, abril de 2004; n. 2610, Barómetro Autonómico (Comunidad Valenciana), noviembre de 2005. 


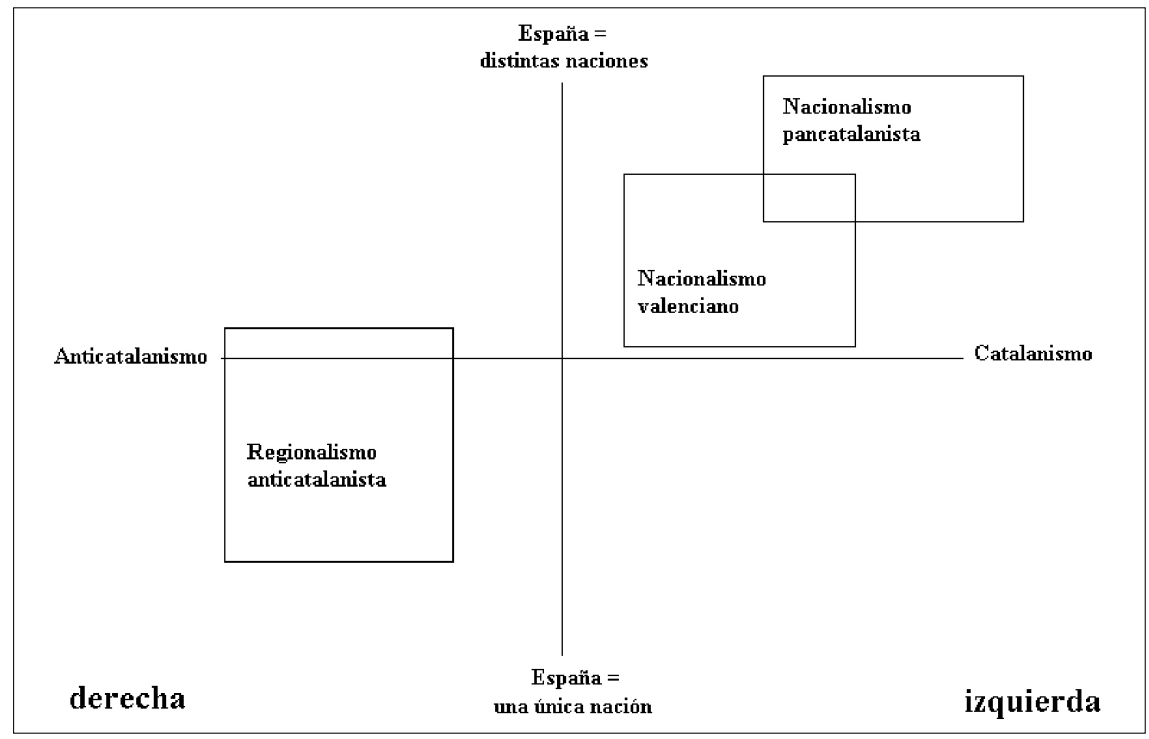

Gráfico 1. Fracturas identitarias y posición predominante de los distintos valencianismos Fuente: elaboración propia.

La primera de las concepciones valencianistas contemporáneas es la que ha tenido la repercusión política directa más minoritaria, si bien ha influido o ha ayudado a generar las otras dos. Tiene su origen en las reflexiones políticas de Joan Fuster, iniciadas en 1962 con el libro Nosotros los valencianos, con el cual consiguió una relativamente intensa influencia en el mundo intelectual y universitario progresista, sobre todo en los años setenta y ochenta, puesto que influenció a parte de las elites políticas de la transición, especialmente en los partidos de izquierda y nacionalistas. Corresponde al nacionalismo pancatalán, que entendería el territorio valenciano como parte de una única nación catalana (Países Catalanes) junto a Cataluña, Baleares, Andorra, la Cataluña francesa y algunas comarcas de Aragón. En términos generales, aspira a convertir los Países catalanes en un estado dentro de una España plurinacional o independiente en Europa y define a España como un estado plurinacional. Su proyecto nacional es de base lingüístico-cultural, según el cual el territorio nacional se corresponde con el área donde se habla la lengua catalana, si bien los ciudadanos catalanes podrían ser todas las personas que viven habitualmente en los Países Catalanes. Su actividad política ha sido puntual, casi marginal y limitada exclusivamente a las comarcas valencianas catalanohablantes. La principal fuerza política de este valencianismo ha sido Esquerra Republicana del País Valencià (ERPV), forma valenciana de Esquerra Republicana de Catalunya (ERC), que compite electoralmente desde finales de los años noventa con resultados irrelevantes (voto en urna inferior al 0,5\%) y algún concejal aislado en el ámbito municipal. 
El segundo valencianismo, el más constante políticamente en el tiempo, corresponde al nacionalismo valenciano, que se asienta también en el pensamiento fusteriano o en revisiones de las tesis fusterianas, entiende el País Valenciano como una nación (a menudo en estrecha relación con las naciones catalanas) o como un ámbito de acción política nacional y combatiría la despersonalización de los valencianos como pueblo singular. Niega también la existencia de una única nación española y cree que España es un estado plurinacional; pero no reivindica, salvo grupos muy minoritarios, la independencia de la nación valenciana dentro de Europa, sino mayor autogobierno. Hasta los años noventa, este nacionalismo no ha diferenciado claramente los límites ni las características de la nación de los valencianos. En un primer momento, su discurso nacional era muy semejante al del pancatalanismo en lo que respecta a la identidad valenciana y, además, a pesar de que tenía el valenciano como único ámbito de acción política, no aclaraba si la nación final que se aspiraba a construir eran los Países Catalanes o el País Valenciano, o si la única razón de ser era tan sólo normalizar el uso social de la lengua catalana y la defensa de las particularidades culturales valencianas (sin una aspiración nacional definida); sin embargo, desde los años noventa, ha ido afirmando la existencia de la nación valenciana sobre fundamentos históricos, institucionales y cívicos, que comparte rasgos nacionales (lengua, parte de la cultura y la historia) con los otros países de lengua catalana. Política y electoralmente, se ha manifestado a través de Unitat del Poble Valencià (UPV), después Bloc Nacionalista Valencià (BNV) y otras pequeñas formaciones. Ha conseguido, en función de las elecciones, entre el $2 \%$ y el $6 \%$ de los votos y ha accedido al Parlamento valenciano en dos legislaturas, siempre en coalición con Esquerra Unida (EU) y siendo el tercer partido en número de concejales, a gran distancia del PP y de los socialistas, en las elecciones locales de 2003 y 2007.

El tercero de los valencianismos, en el que centraremos nuestra atención, es el regionalismo anticatalanista. Se trata del único valencianismo que, de la mano de Unió Valenciana, ha conseguido representación y protagonismo institucional de manera autónoma en todos los ámbitos de representación (ayuntamientos, Cortes Valencianas y Congreso de los Diputados), especialmente entre 1986 y 2000.

Entre el regionalismo anticatalanista y los otros valencianismos, la divergencia es radical y polarizada, y, consecuentemente, las relaciones y las dinámicas de colaboración han sido prácticamente inexistentes. Entre los valencianismos nacionalistas, la cercanía es mayor, ya que, en gran medida, comparten parte del discurso originario; si bien las distancias han ido aumentando con el paso del tiempo cuando los partidos nacionalistas valencianos han tratado de afirmar una realidad nacional valenciana singular. Dentro de los ejes de fractura política, el pancatalanismo se situaría mayoritariamente en la izquierda y en la izquierda extrema, en la consideración de España como estado plurinacional del que los Países Catalanes deben ser independientes y en la catalanidad nacional y lingüística del País Valenciano; el nacionalismo valenciano lo haría en la izquierda, el centro-izquierda y, en menor medida, el centro-derecha, en 
la consideración de España como un estado plurinacional y en la catalanidad lingüística del valenciano; y el regionalismo anticatalanista lo haría mayoritariamente en la derecha, en una concepción de España como una única nación de la que la región valenciana formaría parte y en el anticatalanismo más o menos radical.

\section{Los discursos en torno a la identidad valenciana: el anticatalanista identitario}

La historia política contemporánea valenciana y española tiene sus orígenes últimos en la restauración borbónica de 1874 . El sistema político liberal y conservador de dicha restauración se asentó en el territorio valenciano sin grandes problemas. En el ámbito identitario, sectores de las elites burguesas, sobre todo, de la ciudad de Valencia, encabezados por Teodoro Llorente, principal dirigente de la juntas provinciales del Partido Conservador, apoyaron la Renaixença valenciana; es decir, la recuperación del uso culto y público de la lengua catalanovalenciana, en estrecha relación con el movimiento cultural del mismo nombre en Cataluña. Sin embargo, la Renaixença valenciana tendrá tres diferencias básicas con respecto a la catalana: el uso culto y público de la lengua se limita a la poesía y a los juegos florales; la mayoría de los renacentistas valencianos denominarán a la lengua compartida por catalanes, baleares, andorranos, valencianos y parte de aragoneses con el equívoco nombre de lemosin, nuestra lengua, lengua materna, lengua de los valencianos, además del popular de valenciano, y no utilizarán, salvo contadas excepciones, el de catalán; y, finalmente, el uso culto de la lengua no va acompañado de ningún tipo de reivindicación política valencianista y Llorente rechazará repetidamente la politización catalanista de la Renaixença catalana, ya que, en su opinión, el uso poético de la lengua materna no debía suponer poner en cuestión ni la unidad de la nación española, ni la estructura territorial del poder, ni la división del antiguo Reino de Valencia en tres provincias, ni tampoco la preeminencia social del castellano sobre el valenciano/catalán, en un momento en el que la mayor parte de la burguesía urbana valenciana comienza a abandonar el valenciano/catalán a favor del castellano.

Habrá que esperar, a principios del siglo XX, a que aparezcan las primeras manifestaciones del valencianismo político y los primeros partidos nacionalistas valencianos de base social pequeño burguesa e ideología crecientemente republicana y progresista, que no conseguirán, a pesar de algunas iniciativas modestas, poner en marcha en 1907 una solidaridad valenciana similar a la Solidaritat Catalana de 1906, ni estructurar una plataforma para conseguir una mancomunidad de provincias como la Mancomunitat Catalana de 1914, ni que se aprobase un estatuto de autonomía para el País Valenciano antes del final de la Guerra Civil. En el debate identitario, el valencianismo político del primer tercio del siglo Xx limitaba sus proyectos nacionalitarios al ámbito territorial valenciano y a la consecución de algún tipo de autonomía política dentro de España, reconociendo las vinculaciones históricas, lingüísticas y cultu- 
rales con el resto del área de habla catalana y la necesidad de algún tipo de colaboración con estos territorios.

Además del histórico particularismo identitario valenciano, derivado del hecho de que el antiguo Reino de Valencia fue siempre, durante la época foral, una realidad política diferenciada dentro de la Corona de Aragón (1238-1707) y de la denominación de la lengua catalana en este territorio con el nombre de valenciano desde el siglo XV; hay que entender que, en la Restauración, tienen su origen tres factores esenciales que explican las diferencias del debate identitario valenciano respecto a Cataluña. El primero es que la mayor parte de la burguesía valenciana defendía políticas económicas librecambistas, a diferencia de la burguesía catalana, donde predominaban los intereses proteccionistas, y, por lo tanto, la elites económicas (y también políticas) valencianas se integraba sin ningún tipo de reticencias ni dificultades especiales en el sistema político español de la Restauración y se verán menos afectadas económicamente por el desastre de 1898. El segundo es que en los territorios valencianos no existía un valencianismo popular ni cultural comparable al catalán en aquellos momentos. Y el tercero es que la tradición republicana federal, importante tanto en Cataluña como en el País Valenciano a finales del siglo XIX, fue recogida esencialmente por el blasquismo en Valencia, un movimiento político que siguió una trayectoria política similar al republicanismo lerrouxista español y que se caracterizó por su especial hostilidad, desde sus inicios, tanto hacia el movimiento de la Renaixença valenciana por su carácter conservador y por recuperar el uso culto del catalán/valenciano como a cualquier tipo de solidaridad valenciana o de colaboración entre el naciente nacionalismo valenciano y los movimientos similares catalanes, no tanto por catalanes cuanto por catalanistas; lo cual dio lugar a lo que podríamos denominar el primer anticatalanismo político valenciano de carácter netamente españolista y reivindicador del uniformismo castellanista nacional español, contrario a cualquier nacionalismo que no fuera el español.

Tras la Guerra Civil, con la instauración de la Dictadura franquista, el nacionalismo español radical y patriotero fue la ideología identitaria oficial y dominante en la Comunidad Valenciana, si bien, a partir de 1944, con la fundación de la Editorial Torre, se inician tertulias y la edición de libros en valenciano/catalán y se estructuran algunos círculos intelectuales valencianistas que defienden la unidad lingüística y cultural de los territorios de lengua catalana.

Dicho de otro modo, hasta los años sesenta del siglo XX, las manifestaciones de sectores de la sociedad valenciana que pudieran ser consideradas como contrarias a aspectos de lo catalán nunca plantearon que existiese una escisión identitaria radical entre Cataluña y el País Valenciano o que la lengua propia de estos territorios fuese una lengua diferente. Cuando se produzcan movimientos de oposición a iniciativas catalanas, lo serán contra propuestas de política económica, contra proyectos políticos nacionalistas catalanes, como Solidaritat Catalana, y se defenderá un nacionalismo español castellanista, o se manifestará la desconfianza de la Renaixença valenciana hacia la aspiración de los renacentistas catalanes de un uso público, social, oficial y político normal de la lengua compartida con Cataluña. 
Durante los años sesenta, se abre una época de cambios sociales, económicos y políticos especialmente intensos en el País Valenciano. En lo identitario, el crecimiento económico de los años sesenta aceleró los procesos de cambio y de sustitución lingüística que vivía la sociedad valenciana, tanto por el abandono de la lengua por parte de la burguesía y la pequeña burguesía urbana, como por la llegada masiva de inmigrantes castellanohablantes que se asentarán en las principales ciudades y áreas metropolitanas del país. Pero, a la vez, las transformaciones económicas provocan el nacimiento de una nueva burguesía de servicios e industrial sobre la base de las pequeñas empresas, que tiene intereses distintos de la burguesía tradicional, es mayoritariamente valencianohablante y genera expectativas en el nuevo nacionalismo valenciano, que, ocasionalmente, ve en ella un grupo llamado a liderar o a formar parte de una especie de bloque social nacionalmente consciente. Del mismo modo, en algunos ámbitos universitarios, hay un interés creciente por convertir al País Valenciano en objeto de estudio académico, lo que contribuirá también a desarrollar el valencianismo político. Y todo ello en un momento en el que se está configurando una nueva oposición al franquismo, que estará formada por personas con escasas relaciones con las tradiciones y los imaginarios políticos de la Segunda República y de la Guerra Civil española.

En este contexto de cambio social, de pérdida de homogeneidad de la comunidad lingüística valencianocatalana, de aparición de nuevos sectores sociales emergentes y de nuevos grupos intelectuales, así como de una oposición política al franquismo postrepublicana con influencias valencianistas, se produce, bajo el influjo intelectual de Joan Fuster, la teorización de un nuevo valencianismo que pone el acento en las coincidencias entre las distintas sociedades del dominio lingüístico catalanovalenciano y en la definición de la lengua como elemento determinante del proyecto nacional. La reflexión fusteriana trascenderá, de este modo, la tradición valencianista anterior e introducirá al menos dos novedades principales y radicales. En primer lugar, la nación es definida a partir de la lengua y, consecuentemente, el ámbito nacional último de los valencianos serán los Paises Catalanes, propuesta de nación catalana que se identifica a grandes rasgos con el dominio lingüístico valencianocatalán ${ }^{1}$ y que rompe con el valencianismo anterior a la Guerra Civil, que hacía de la tradición histórica del antiguo reino (y también de la lengua) el elemento vertebrador del país. En segundo lugar, Fuster critica radicalmente el comportamiento lingüístico y nacional de las elites políticas y sociales valencianas en los últimos siglos y hace una impugnación especialmente intensa de la función nacional de la burguesía valenciana desde la Restauración hasta nuestros días, a causa de su integración provinciana en el proyecto nacional español y su falta de voluntad como clase dirigente de la sociedad valenciana. La tesis fusteriana era

1. La idea de la Gran Cataluña como espacio pancatalán ya había sido utilizada por el catalanismo de principios del siglo XX, pero sin una formulación muy clara. Serán el valenciano Joan Fuster y, en menor medida, el mallorquín Josep Maria Llompart quienes la teoricen y difundan en los años sesenta y setenta. 
que, en el País Valenciano, no había habido una clase dirigente con voluntad de liderar nacionalmente el país, y que el comportamiento tradicional de la burguesía había sido antivalenciano y lingüísticamente castellanizador. Esta crítica comportaba una demanda de cambio de las futuras y nuevas elites democráticas, concluyendo que el futuro de la lengua y la recuperación nacional valenciana debían pasar por una izquierda nacionalmente consciente y por la marginación política de la burguesía tradicional valenciana. Este análisis influirá, con una intensidad desigual pero significativa, en el valencianismo, en sectores de la oposición antifranquista y en una parte importante de los círculos intelectuales y universitarios de los años setenta y primeros ochenta; contribuyendo a incorporar al debate y a los programas políticos de la oposición al franquismo el problema nacional valenciano, y, sobre todo, generará un contradiscurso anticatalanista nuevo que tendrá su origen en sectores de la derecha y que definirá la identidad lingüística y cultural propia, negando cualquier rasgo común entre lo valenciano y lo catalán, ideas que, a lo largo de cinco fases temporales, han acabado siendo asumidas por buena parte de la sociedad valenciana $^{2}$.

De hecho, inmediatamente después de la publicación del Nosotros los valencianos de Fuster en 1962, desde los ámbitos intelectuales conservadores vinculados al franquismo local, hay una respuesta crítica y radicalmente opuesta a sus tesis, prácticamente sin oportunidad de entablar ningún debate público y plural, y utilizándose los medios de comunicación públicos y privados vinculados al régimen franquista, para atacar a la traición catalanista de Fuster y negar sus ideas. En estas críticas a Fuster, se afirmará por vez primera que el valenciano es una lengua distinta del catalán y se pondrán las bases de un con-

2. Desde una perspectiva histórica, el anticatalanismo identitario valenciano tiene cinco fases distintas sin rupturas entre ellas. Una primera que corresponde con el franquismo de los años sesenta y setenta, en los que se articula un primer discurso antifusteriano; una segunda, que corresponde a los años que van de la muerte de Franco a las primeras elecciones locales (1975-1979), en los que las autoridades franquistas de la Diputación y el Ayuntamiento de Valencia, junto con AP, recuperan el discurso antifusteriano de la década anterior; una tercera, en torno al proceso autonómico (1979-1982), en el que el anticatalanismo identitario, impulsado por UCD, se convierte en un movimiento de masas y convive con manifestaciones agresivas y violentas. Una cuarta, desde mediados de los ochenta y durante los noventa, en la que el movimiento se modera formalmente, se concentra políticamente en UV y, en menor medida, en el PP, y reduce las formas más violentas. Y, finalmente, una quinta, desde finales de los noventa, en la que el PP es el principal partido anticatalanista y en la que el rechazo anticatalán persigue no tanto negar la unidad lingüística, cuanto provocar una especie de aislamiento y extrañamiento de la Comunidad Valenciana respecto a Cataluña y el catalán. El anticatalanismo identitario valenciano tenía, durante las dos primeras fases, la intención de combatir la oposición política e intelectual al franquismo; después de las primeras elecciones democráticas, en manos de UCD, sirvió como instrumento para desgastar a la izquierda y al nacionalismo valenciano, y, finalmente, se ha convertido en un lugar común de parte de la sociedad valenciana, especialmente de sus elites económicas y políticas, que ha contribuido a la falta de relaciones normalizadas entre Cataluña y la Comunidad Valenciana, y a que la izquierda valenciana carezca de un discurso identitario valenciano sólido. 
tradiscurso anticatalanista identitario valenciano que se opondrá a cualquier grado de catalanidad lingüística, cultural y, menos aún, política del País Valenciano históricamente o contemporáneamente ${ }^{3}$, lo cual da pie a considerar que el valenciano corre peligro de ser sustituido por el catalán a causa de las iniciativas de los catalanistas, de manera que el término catalanista adquiere una connotación negativa entre buena parte de la población, especialmente en las comarcas cercanas a la ciudad de Valencia, y se convierte en una descalificación política radical, sinónimo de antivalencianos y de traidores a la auténtica patria valenciana.

No se debería magnificar la capacidad de influencia política de las tesis fusterianas, del nacionalismo valenciano y del valencianismo en general antes de la muerte de Franco. De hecho, la concepción fusteriana sobre la realidad nacionalitaria valenciana parece ser importante políticamente sólo en la medida en que, con el inicio de la transición, aparecen nuevas fuerzas políticas (UCD, PSPV-PSOE) que incorporan a personas y a grupos influidos por el pensamiento fusteriano, y cuando las reivindicaciones autonómicas se convierten en una prioridad inmediata del nuevo sistema democrático. Habida cuenta de que, además, el anticatalanismo aparece al comienzo de la transición como un fenómeno políticamente muy limitado y en proceso de desaparición, ya que sólo afectaba a elites del franquismo institucional y en las primeras elecciones democráticas (1977), únicamente AP, entonces un partido menor, posfranquista y antiautonomista, fundamentó parte de su programa electoral en el anticatalanismo identitario.

Las primeras elecciones generales de 1977 dieron un resultado imprevisto en el País Valenciano: el PSOE-PV, y no UCD, fue el partido más votado. Los partidos de izquierda (PSOE, PCE y PSP) superaron a los de derecha (UCD

3. Para negar la catalanidad lingüística del valenciano, se afirmará, en primer lugar y contra toda evidencia histórica, que, en la época islámica, los musulmanes que vivían en lo que sería después la parte valencianohablante de la Comunidad Valenciana habrían hablado una lengua latina mozárabe que sería el origen del valenciano actual. La interpretación mozarabista quería negar que el valenciano era un producto de la repoblación catalanoaragonesa; pero su endeblez era evidente, ya que tan sólo la parte catalanohablante de la Comunidad Valenciana sería una isla mozárabe, mientras que no se niega la repoblación castellana y aragonesa de las comarcas valencianas castellanohablantes y tampoco existen islas mozárabes en el sur de Castilla, en la Mancha, en Andalucía ni en Extremadura, donde se acepta que los dialectos del castellano que se hablan actualmente son producto básicamente de la repoblación castellana medieval. Teniendo en cuenta la debilidad de la teoría mozarabista, el secesionismo lingüístico valenciano ha defendido la tesis más moderna y más sólida de que la lengua la hace el pueblo, según las cual la voluntad política del pueblo respecto a la identidad de la lengua sería la que determinaría su existencia diferenciada respecto de otras lenguas semejantes. Dicho de otro modo, no se negaría necesariamente una primitiva y medieval unidad lingüística del catalán y el valenciano, pero sí que el catalán y el valenciano sean ahora una misma lengua, y no por razones científico-lingüísticas, sino simplemente porque los valencianos no desean formar parte de la comunidad lingüística catalana, siguiendo, paradójicamente, la argumentación implícita del pancatalanismo, según la cual quien habla catalán es (identitaria y nacionalmente) catalán, pero afirmando que, puesto que los valencianos nacionalmente no son catalanes, el valenciano no es catalán. 
y AP), y el nacionalismo valenciano obtuvo unos resultados poco relevantes. Fue entonces, cuando se inició el proceso constituyente en España y el proceso autonómico valenciano, cuando la dirección valenciana de UCD estableció una nueva estrategia, orientada a desgastar a los partidos de izquierda y frenar las expectativas autonómicas valencianas, y para hacerla triunfar denunciarán el catalanismo de los partidos de izquierda y darán apoyo económico y mediático a grupos anticatalanistas que cuestionarán la unidad de la lengua catalana y atacarán, a menudo violentamente (bombas, agresiones, tumultos, boicot a actos públicos) y siempre exaltadamente y generalmente sin intervención policial, a cualquier iniciativa considerada catalanista.

Con el cambio de estrategia de UCD, el anticatalanismo valenciano dejará de tener una influencia minoritaria y pasará a ser un movimiento con capacidad de penetración y movilización social amplia, especialmente en el área metropolitana de Valencia y en la provincia de Valencia, que acabará aglutinando políticamente a sectores de las clases medias tradicionales, propietarios agrícolas y pequeños empresarios, alrededor de una serie de ideas, generalmente negativas, bastante simples y con un fuerte contenido emocional, estructuradas en torno a la dinámica amigo/enemigo, que niega, como hemos dicho, la catalanidad lingüística del valenciano, rechaza cualquier tipo de similitud entre el País Valenciano y Cataluña, mientras afirma la existencia de un supuesto imperialismo catalán que pretende apropiarse de la cultura y la lengua valencianas y se exaltan de manera acrítica algunos de los aspectos más tópicos, tradicionales y subalternos del pueblo valenciano.

Del mismo modo, el anticatalanismo identitario se convirtió en un movimiento sociopolítico populista que, en el eje derecha-izquierda, contó con simpatizantes y activistas de todo el espectro ideológico de la derecha y con minorías de la izquierda más tradicional; mientras que, en el eje españolismo-valencianismo, se trata de una masa social básicamente nacionalista española poco pluralista y regionalista, pero donde convivirán también grupos minoritarios de nacionalistas valencianos; en cualquier caso, predominarán notablemente las posiciones conservadoras y el regionalismo no reivindicativo, a menudo con comportamientos antidemocráticos, antipluralistas y virulentos (ver gráfico 1).

Las tres paradojas principales del anticatalanismo identitario valenciano serán, en primer lugar, una estructuración del discurso sobre la identidad valenciana, basado, como en el caso fusteriano, en la lengua, pero con un planteamiento negativo, ya que afirma que la identidad de los valencianos es diferente a la de los catalanes y niega que hablen una misma lengua. La segunda paradoja aparente deriva del hecho de que su movilización social y política nunca se dirigirá a reivindicar un nivel de autogobierno más elevado o a defender políticas para conseguir la extensión del uso social de la lengua valenciana o su normalización, sino, que durante la transición, contribuyó a la paralización y reconducción del proceso autonómico valenciano hacia un grado de autogobierno inferior al de Andalucía, Cataluña, el País Vasco o Galicia, y, posteriormente, ha tendido a oponerse a las políticas públicas de promoción y nor- 
malización lingüística, alegando que constituían instrumentos para despersonalizar al pueblo valenciano y para catalanizar la lengua propia. La última de las paradojas es que, a pesar de afirmar que se trata de un movimiento de todos los valencianos, su ámbito de acción política se concentra básicamente en la ciudad y parte de la provincia de Valencia, y es poco significativo en el resto de la Comunidad Valenciana.

En términos de representación política, el regionalismo anticatalanista valenciano estuvo vinculado directamente a UCD, hecho que explica que el primer representante anticatalanista que llegó a las instituciones valencianas fuese Rafael Orellano, presidente de la principal y una de las más agresivas asociaciones anticatalanistas, el Grup d'Acció Valencianista (GAV), y lo hace por las listas municipales de la UCD en la ciudad de Valencia en las elecciones locales de 1979. De hecho, aunque existieran pequeñas formaciones regionalistas relativamente autónomas de UCD, como Unió Regionalista Valenciana (URV), no fue hasta la desaparición de la UCD (1982) cuando los partidos regionalistas empezaron a tener una importancia política destacable de la mano del proyecto de Fraga de crear una gran coalición de derechas regionales en torno a AP, el partido hegemónico entonces de la derecha valenciana. Fue en ese nuevo contexto cuando, a principios de los años ochenta, se creó Unió Valenciana y el anticatalanismo identitario valenciano inició una nueva etapa y contó con un partido propio que lo representaba y que estructuraba toda su acción política en combatir la supuesta catalanización de la sociedad valenciana.

Con todo, e independientemente de la evolución de UV, en términos relativos, el éxito, en las últimas décadas, de la contrainterpretación anticatalanista ha conseguido una notable influencia social, muy superior a la de otros valencianismos que definen, como era tradicional, que la lengua y la cultura valencianas forman parte de un sistema compartido catalanovalenciano. Entre otras causas, la hegemonía relativa del anticatalanismo como ideología identitaria mayoritaria se debe a que el valencianismo anticatalanista es básicamente emotivo, no plantea ninguna contradicción con el españolismo castellanista tradicional, con el que no entra en conflicto al no cuestionar el predominio lingüístico del castellano y no comporta ningún compromiso personal o colectivo con el uso social del valenciano. Mientras que el valencianismo particularista, el nacionalismo valenciano y, más aún, el nacionalismo catalanista, se estructuran sobre principios más racionalistas, son conflictivos con el españolismo castellanista, cuestionan, en mayor o menor medida, la subordinación social del valenciano/catalán y suponen una tensión identitaria superior y un compromiso personal y colectivo más elevado en torno a la lengua propia.

\section{Historia breve de Unió Valenciana}

Políticamente, como hemos visto, el anticatalanismo identitario valenciano está vinculado desde sus inicios, y en cada una de sus distintas fases evolutivas, con la derecha de la ciudad y la provincia de Valencia, que, tanto durante el franquismo, como en la democracia, forma parte sin fisuras de la dere- 
cha española dominante en cada momento. Así había ocurrido en los años sesenta, en el tardofranquismo y durante el proceso de acceso a la autonomía con UCD, y así ocurrirá, con matizaciones, con Unió Valenciana, un partido que seguirá una vida paralela a la de AP/PP: subordinada y subalterna a AP en su creación, autónoma y con una colaboración competitiva en sus años de crecimiento, y nuevamente vinculada de manera crecientemente subordinada al PP durante su decadencia.

De hecho, en la fundación de Unió Valenciana, el 30 de agosto de 1982, pensando en las elecciones generales de aquel año, tuvo un protagonismo decisivo, además del empresario Vicente González-Lizondo, el último alcalde franquista de Valencia y procurador en las Cortes de la Dictadura, Miguel Ramón Izquierdo ${ }^{4}$, persona con una estrecha relación con Manuel Fraga, presidente de AP e impulsor, en 1982, de Coalición Popular, convergencia de partidos conservadores (AP, liberales, democristianos, regionalistas de derecha). Es decir, la fundación y los primeros pasos de UV, dirigida por González-Lizondo y Ramón Izquierdo, estuvieron propiciados por Alianza Popular y por la estrategia de este partido de sumar el mayor número de fuerzas de derecha en torno suyo.

Poco después, en las elecciones locales y a las Cortes Valencianas de 1983, UV volvió a formar parte de la Coalición Popular en los mismos términos que un año antes, lo que permitió que algunos de sus militantes fueran concejales y diputados valencianos sin mayor trascendencia en la vida política. Sin embargo, las dificultades de AP para atraer al centro-derecha más moderado que o bien se había abstenido, o bien había votado a UCD, CDS y al mismo Partido Socialista en 1982, y el crecimiento de las expectativas electorales del CDS, llevaron, en 1985, a una Unió Valenciana, en la que se había consolidado el liderazgo de Vicente González-Lizondo, a decidir abandonar la Coalición Popular y a presentarse en solitario a las siguientes elecciones generales, locales y autonómicas. Fuera de Coalición Popular, UV consiguió unos resultados más discretos de lo que esperaba ${ }^{5}$. Aunque Miguel Ramón seguía siendo diputado en las Cortes Generales, obtuvo 6 diputados y cerca de 200.000 votos en las elecciones autonómicas, contaba con más de 200 concejales y algunos alcaldes y, sobre todo, se convirtió en el primer partido de centro-derecha en la ciudad de Valencia, por delante del PP y del CDS. Sin embargo, a pesar de que el centro-derecha tenía mayoría de concejales, no fue capaz de llegar a ningún acuerdo, ni después de las elecciones ni a lo largo de la legislatura, a diferencia

4. Ramón Izquierdo fue diputado en el Congreso entre 1982-1989, primero dentro de Coalición Popular (1982-1986) y en la legislatura siguiente por UV de manera autónoma.

5. Cuando UV decidió presentarse a las elecciones de manera autónoma, hizo públicas encuestas que auguraban cerca de un millón de votos para la derecha y el centro-derecha valencianos que se repartía casi al 50\% entre UV y AP. En las elecciones generales de 1986, el centro-derecha obtuvo 851.368 votos (AP: 603.231; CDS: 183.734, y UV: 64.403) y en las autonómicas de 1987 alcanzó los 885.303 votos, con lo que UV y CDS crecieron en detrimento de AP (AP: 476.099; CDS: 225.663, y UV: 183.541). 
de lo que sucedió en Madrid, por lo que el PSPV-PSOE gobernó en minoría a pesar de sufrir el abandono del alcalde a mitad de la legislatura ${ }^{6}$.

Durante aquella legislatura como partido autónomo, Unió Valenciana fue capaz de atraer a algunos dirigentes y cuadros de AP/PP e, incipientemente, también del CDS; marcó distancias formales con el PP y definió como objetivos básicos ganar la alcaldía de Valencia y disputarle la hegemonía política del voto conservador al PP, primero en la provincia de Valencia y luego en toda la Comunidad Valenciana. En las elecciones siguientes, UV consiguió los mejores resultados de su historia, pasó de uno a dos representantes en el Congreso de los Diputados en 1989 y en las elecciones locales y autonómicas de 1991 obtuvo los mejores resultados absolutos y relativos del partido; pero, sin embargo, no consiguió ninguno de sus objetivos: UV no fue la fuerza de la derecha más votada en la ciudad de Valencia, con el 21,8\% de los votos y 8 concejales, sino que lo fue el PP, con el 27,4\% y 9 concejales, por 13 concejales del PSPV-PSOE y 3 de EU, lo que llevó a Rita Barberá (PP) a la alcaldía de Valencia, y quedó muy lejos también de superar al PP en la provincia de Valencia (23,5\% PP y 16,4\% UV) y más aún en el conjunto de la Comunidad Valenciana (28,1\% PP y $10,5 \%$ UV).

A partir de este momento, que coincide también con la reorganización de la derecha española en torno al PP liderado por Aznar, UV comienza una progresiva decadencia, a pesar de que incorporará a sus filas algunos cuadros y dirigentes del CDS. De este modo, en las elecciones generales de 1993 sólo conservará uno de los dos diputados en su poder y en las elecciones locales y autonómicas de 1995 pierde un 20\% de sus votantes (de 208.126 en las autonómicas de 1991 a 165.959) y dos diputados, pierde concejales en toda la Comunidad Valenciana, y en la ciudad de Valencia se queda tan sólo con la mitad de los votos (40.000) y tres de los ocho concejales que había conseguido cuatro años antes. Con todo, y a pesar de los relativamente malos resultados, Unió Valenciana se convirtió, en las elecciones autonómicas, en el partido que decidía el gobierno de la Generalitat Valenciana entre PP (42 diputados) o PSPV-PSOE y EU (42 diputados). Optó por el PP después de un largo período de negociación y el denominado pacto del pollo, lo que convirtió a Eduardo Zaplana presidente del Gobierno Valenciano ${ }^{\circ}$.

6. El candidato de UV a la alcaldía de Valencia fue González-Lizondo. UV consiguió el 20,1\% de los votos (77.353) y 7 concejales; AP, el 19,2\% y otros 7 , y el CDS, el 11,5\% y 4 concejales. El centro-derecha sumó 18 concejales por 13 PSPV-PSOE y 2 EU. En 1987, no hubo acuerdo entre las fuerzas de centro-derecha; pero, en diciembre de 1988, la dimisión del alcalde socialista abrió una grave crisis en el partido del Gobierno, UV y AP iniciaron conversaciones para presentar una moción de censura, pero AP se opuso a que el candidato fuera González-Lizondo, para evitar su consolidación como líder, y propuso un candidato de consenso, lo que impidió que la moción siguiera adelante.

7. El pacto del pollo se refiere al acuerdo de gobierno entre el PP y UV, y recibe ese nombre por dos motivos distintos: porque se culminó la noche del 4 de julio de 1995, bajo la presión de la patronal valenciana y en el despacho de un empresario avícola, y porque GonzálezLizondo, al ser preguntado durante la negociación, afirmó que estaban aclarando a quién le correspondía el muslo y a quién la pechuga del pollo. 
El pacto otorgaba a UV la presidencia de las Cortes Valencianas en la figura de Vicente González-Lizondo y una de las diez consejerías del Gobierno Valenciano (Medio Ambiente, Agricultura y Pesca, para Maria-Àngels RamonLlin), además de la presencia de miembros de UV en empresas públicas. Pero con el acceso de UV al Gobierno Valenciano en coalición con el PP, se multiplicarán los problemas de este partido, tanto por las tensiones internas, como por su difícil relación de colaboración y competencia con su socio de gobierno. En lo que se refiere a las tensiones internas, éstas tienen su origen en una progresiva división interna que agrupará, por un lado, a quienes consideran que el pacto con el PP perjudica a Unió Valenciana, quienes piensan que UV debe ser una formación centrista y quienes desean convertirla en un partido nacionalista moderado y reducir la virulencia de su discurso anticatalanista; mientras que, en torno al presidente del partido (González-Lizondo), se sumarán aquéllos que defienden la colaboración con el PP y el mantenimiento de un partido básicamente regionalista y anticatalanista. Esta división se mantendrá durante todo el proceso de descomposición de esta formación en los años siguientes, con la predominancia de un sector u otro en función de la coyuntura política y los resultados electorales. El segundo foco de tensión, estrechamente unido al anterior, tendrá su origen en la competencia del PP por conquistar el espacio electoral de UV (ver tabla 2).

En la medida en que se ponga de manifiesto, en los meses siguientes al pacto de gobierno, que el Partido Popular y el presidente de la Generalitat Valenciana, Eduardo Zaplana, son los actores principales del Gobierno Valenciano y la subordinación de UV a la estrategia y la acción de gobierno del PP, los enfrentamientos y las diferencias entre la dirección regionalista y los sectores críticos del partido irán en aumento. Así, por ejemplo, en abril de 1996, las tensiones internas se producirán por el apoyo de UV a la investidura de Aznar como presidente del Gobierno de España, posteriormente, por las diferencias entre UV y el PP en el gobierno del Ayuntamiento de Valencia durante el verano del mismo año, por la expulsión de la dirección de las juventudes de UV por excesivamente nacionalistas meses después y culminan, finalmente, el 30 de noviembre de 1996, en la decisión, poco habitual en un partido político, de que el Consell Nacional de UV expulsara a su presidente, Vicente González-Lizondo, y nombrara al diputado de las Cortes Valencianas, Hèctor Villalba, del sector hasta entonces crítico, nuevo líder del partido. Además, se dio la circunstancia de que, en la madrugada del 20 de diciembre, González-Lizondo sufrió un infarto durante un largo pleno parlamentario y moría tres días después, por lo que la presidencia de las Cortes pasó a manos de Hèctor Villalba, y González-Lizondo se convirtió en una especie de mártir entre sus seguidores, imagen que fue alimentada por el Partido Popular valenciano.

La nueva dirección de UV, de la que formaban parte tanto Hèctor Villalba como el concejal de Valencia Társilo Piles y antiguos dirigentes del CDS, como Fermín Artagoitia, trató de establecer una estrategia casi imposible de distanciamiento y semioposición con el PP, sin romper el pacto de gobierno en la 
Tabla 2. Resumen de la historia de UV (1982-2008)

\begin{tabular}{|c|c|c|c|c|c|}
\hline Años & $\begin{array}{l}\text { Presidente } \\
\text { de UV }\end{array}$ & $\begin{array}{c}\text { Relación } \\
\text { con AP/PP }\end{array}$ & $\begin{array}{l}\text { Posiciones políticas } \\
\text { dominantes }\end{array}$ & $\begin{array}{l}\text { Ámbitos de } \\
\text { representación }\end{array}$ & $\begin{array}{l}\text { Importancia } \\
\text { política }\end{array}$ \\
\hline $1982-1985$ & Vicente González-Lizondo & Coalición electoral & $\begin{array}{l}\text { Regionalismo españolista. } \\
\text { Anticatalanismo. } \\
\text { Populismo conservador. }\end{array}$ & $\begin{array}{l}\text { Congreso de Diputados. } \\
\text { Cortes Valencianas. } \\
\text { Ayuntamientos (pocos) } \\
\text { (en coalición con AP). }\end{array}$ & Baja \\
\hline 1986-1995 & & Colaboración municipal & & $\begin{array}{l}\text { Congreso de Diputados } \\
\text { Cortes Valencianas } \\
\text { Ayuntamientos }(20 \%)\end{array}$ & Media \\
\hline $1995-1996$ & & $\begin{array}{l}\text { Gobierno de coalición en } \\
\text { la Generalitat y municipios. }\end{array}$ & & & Alta \\
\hline 1997-1999 & Hèctor Villalba & $\begin{array}{l}\text { Competencia electoral. } \\
\text { Gobierno de coalición } \\
\text { (y semioposición) en la } \\
\text { Generalitat y municipios. }\end{array}$ & $\begin{array}{l}\text { Protonacionalismo. } \\
\text { Centrismo. } \\
\text { Menor virulencia } \\
\text { anticatalanista. }\end{array}$ & & Alta \\
\hline $1999-2000$ & José María Chiquillo & $\begin{array}{l}\text { Competencia electoral. } \\
\text { Desigual colaboración } \\
\text { en los gobiernos locales. }\end{array}$ & $\begin{array}{l}\text { Regionalismo españolista. } \\
\text { Anticatalanismo. } \\
\text { Populismo conservador. }\end{array}$ & $\begin{array}{l}\text { Congreso de Diputados. } \\
\text { Ayuntamientos }(20 \%) \text {. }\end{array}$ & Baja \\
\hline $2000-2004$ & & & & Ayuntamientos (20\%). & Baja \\
\hline $2004-2005$ & & $\begin{array}{l}\text { Coalición electoral. } \\
\text { Mayor colaboración } \\
\text { en el ámbito local. }\end{array}$ & & $\begin{array}{l}\text { Senado. } \\
\text { Ayuntamientos (13\%). }\end{array}$ & Baja \\
\hline 2005 & Julio Chanza & $\begin{array}{l}\text { Competencia electoral. } \\
\text { Desigual colaboración } \\
\text { en los gobiernos locales. }\end{array}$ & & Ayuntamientos (13\%). & Baja \\
\hline $2005-2006$ & Joaquim Ballester & & $\begin{array}{l}\text { Protonacionalismo. } \\
\text { Centrismo. } \\
\text { Menor virulencia } \\
\text { anticatalanista. }\end{array}$ & & Baja \\
\hline $2006-2008$ & José Manuel Miralles & Competencia electoral. & $\begin{array}{l}\text { Regionalismo españolista. } \\
\text { Anticatalanismo. } \\
\text { Populismo conservador. }\end{array}$ & Ayuntamientos (2\%). & Muy baja \\
\hline
\end{tabular}


Generalitat. En la remodelación y ampliación del Gobierno Valenciano de febrero de 1997, UV presionará y conseguirá contar con dos consejeros (Medio Ambiente, José Manuel Castellá, y Agricultura y Pesca, Maria-Àngels RamonLlin), si bien las competencias que gestionaba eran esencialmente las mismas que antes. En 1997, las tensiones internas, favorecidas por la cada vez más evidente estrategia del PP de atraer votantes y dirigentes regionalistas a sus filas, se evidenciarán en una primera escisión de UV y en el abandono de concejales y militantes lizondistas, que fundarán Iniciativa de Progrés de la Comunitat Valenciana (IPCV), formación que, desde el primer momento, estuvo en la órbita del PP y que se integraría en este partido en las elecciones autonómicas y locales de 1999. Mientras, UV acentúa sus intentos de marcar diferencias con el PP, lo que le llevará a abandonar el gobierno municipal de Valencia en diciembre de 1997 y a especular con una moción de censura junto a los socialistas en el Ayuntamiento, o a que sus dirigentes declaren públicamente, por primera vez en su historia, que UV podía gobernar tanto con el PP como con el PSPV-PSOE; mientras sus diputados, en junio de 1998, votaban junto con la oposición en las Cortes Valencianas, dejando al PP en minoría, y mientras realizan, en noviembre del mismo año, un congreso del partido en el que se pretendía una refundación ideológica moderando su discurso anticatalanista, apuntando posiciones más nacionalistas que regionalistas y distanciándose del discurso más populista y conservador que habían caracterizado a UV hasta entonces, pero sin abandonar el anticatalanismo identitario ${ }^{8}$.

Los últimos intentos de la dirección de UV para distanciarse del PP y reorientar la estrategia del partido de manera sustancialmente diferente a como lo había hecho durante la década anterior, se produjeron en medio de una fuerte ofensiva del PP por atraerse el voto regionalista y conseguir la mayoría absoluta en las Cortes Valencianas, que consistió en homenajes a la bandera autonómica y a la figura de Vicente González-Lizondo por parte del Partido Popular, en nuevas escisiones en UV (Alternativa Valencianista) bien recibidas por el PP y, sobre todo, en la incorporación de cargos públicos y cuadros de UV poco antes de las elecciones locales y autonómicas de mayo de 1999: la más importante, la de Maria-Àngels Ramon-Llin, consejera del Gobierno Valenciano, que abandonó UV en enero de 1999 y se incorporó al PP, pero también concejales, dirigentes y alcaldes de localidades medianas y grandes (Burjassot, Paterna, Llíria, Vallada o Elche), que, de manera intermitente, fueron dejando UV entre enero y abril de ese año. En las elecciones autonómicas y locales, UV hace el esfuerzo de presentar listas electorales en un mayor número de municipios, lo que le permite conseguir una cantidad de concejales similar a la

8. En julio de 1998, el Consell Valencià de Cultura, en un dictamen solicitado por el presidente de la Generalitat Valenciana, reconocía, de hecho, la unidad lingüística catalanovalenciana. El dictamen fue asumido por todas las fuerzas políticas, salvo UV, que votaron a favor o no se opusieron a la creación de la Acadèmia Valenciana de la Llengua, que, asimismo, reconocerá la unidad lingüística y la doble denominación catalán y valenciano para la lengua catalanovalenciana. 
de las elecciones de 1995, pero desciende en número de votos, en número de alcaldes y, sobre todo, queda fuera de las Cortes Valencianas por apenas un $0,24 \%$ de los votos (unos 5.500 votos) y el PP obtiene la mayoría absoluta?

Las consecuencias de esta derrota electoral fueron inmediatas. Se recrudeció la división del partido entre los grupos que podríamos denominar protonacionalistas y anticatalanistas moderados y quienes se mantenían en posiciones esencialmente regionalistas y más exacerbadamente anticatalanistas. En julio de 1999, Hèctor Villalba anuncia que no se presentará a la reelección de la presidencia del partido, lo cual abre una crisis en la dirección que se cerrará con la elección de José María Chiquillo como presidente y un alejamiento de las posiciones más moderadamente anticatalanistas y protonacionalistas. Poco después, en las elecciones generales de marzo de 2000, UV perderá el diputado que tenía en las Cortes Generales y la mitad de los votos de las elecciones anteriores, con lo cual se acelerará un proceso que seguirá en los años siguientes de debilitamiento, abandono de antiguos dirigentes de la formación y propuestas de refundación, problemas de la dirección con las juventudes del partido por lo que consideraban radicalismo nacionalista y cambios internos para intentar reestructurar la formación y establecer alianzas con pequeñas formaciones de ámbito local o comarcal, a fin de recuperar el anticatalanismo como único discurso político.

En las siguientes elecciones locales y autonómicas de 2003, UV sufrirá una nueva derrota electoral y quedará muy lejos de poder acceder a las Cortes Valencianas (3\% de los votos). Tras esta derrota, el presidente y la dirección regionalista optarán por concurrir en coalición con el PP en las elecciones generales de 2004 y acercar UV al Partido Popular (José María Chiquillo sería senador en las listas del PP); decisión que será impugnada judicialmente por buena parte de UV, que la considerará ilegal y que generará una oposición creciente en el seno de UV que acabará provocando la dimisión de Chiquillo como presidente del partido en 2005, quien abandonará UV y fundará Unió de Progrés de la Comunitat Valenciana (UPCV), partido que se integrará en el PP poco después, y la elección en este cargo por unos meses de Julio Chanza, alcalde de Alcàsser, y, después del congreso nacional del partido, de Joaquim Ballester, quien intentará, sin éxito, volver a posiciones moderadas similares a las de Hèctor Villalba. Ballester dimitirá en abril de 2006 como presidente del partido y será elegido en su lugar José Manuel Miralles. En las elecciones locales

9. La estrategia del PP de desgaste a UV (y de favorecer limitadamente al BNV) le dio buenos resultados. En las elecciones autonómicas de 1999, el PP consiguió 49 diputados, de los 89 diputados, por 35 PSPV-PSOE y 5 EU. No obstante, esta clara mayoría del PP hubiera sido más ajustada, si las elecciones a Cortes Valencianas no tuvieran una barrera de exclusión electoral muy elevada ( $5 \%$ de los votos del conjunto de la Comunidad Valenciana): UV quedó fuera del parlamento con un $4,76 \%$ de los votos y el BNV con el $4,60 \%$, lo que dejó a un 9,36\% de votos a candidaturas con apoyo electoral significativo y 210.000 personas sin representación. Con una barrera electoral del 3\%, el PP habría conseguido 46 diputados y la mayoría absoluta (45) del PP hubiera dependido de un número escaso de votos en Alicante y Valencia. 
y autonómicas de 2007, UV obtendrá los peores resultados de su historia (un $0,9 \%$ de los votos autonómicos y unos pocos concejales), mientras que, en las generales de 2008, el partido evidenciará la profunda crisis en la que está sumido, al decidir no presentarse a ellas (ver tabla 2).

Con todo, y más allá de sus conflictos internos, UV ha tenido una presencia territorial y un desarrollo intelectual con todas las limitaciones propias del movimiento anticatalanista: concentración territorial a las comarcas litorales de la provincia de Valencia, beligerancia radical contra los ámbitos universitarios e intelectuales, oposición a las iniciativas de normalización lingüística del valenciano, pobre explicación de la realidad regional o nacional o, simplemente, identitaria valenciana más allá del recurso a los tópicos anticatalanistas, limitada autonomía política de la derecha de ámbito estatal (UCD y AP/PP), sistema de relaciones exclusivamente con partidos regionalistas conservadores, propuestas políticas con escasas iniciativas en positivo y la obsesión de no ser menos que otras comunidades autónomas y, sobre todo, menos que Cataluña.

\section{Comportamiento electoral de UV en el sistema valenciano de partidos}

El sistema de partidos de la Comunidad Valenciana desde las primeras elecciones generales de 1977 hasta la actualidad ha sido dominado por el bipartidismo corregido, aunque durante una legislatura autonómica en la segunda mitad de los ochenta evolucionó hacia un multipartidismo moderado y, desde los años noventa, lo hace hacia un dominio casi exclusivo de los dos grandes partidos. Además, es un sistema en el que la primera fuerza política casi siempre ha tenido una posición hegemónica en términos de apoyo electoral, representación política y poder institucional, ya que acostumbra a tener en su poder el gobierno tanto de los grandes ayuntamientos como de las diputaciones provinciales y del gobierno autonómico.

De este modo, las dos principales fuerzas políticas han concentrado habitualmente más del 75\% de los votos válidos en las elecciones locales, autonómicas y generales, mientras que la proporción de escaños valencianos en su poder en el Congreso de los Diputados y en las Cortes Valencianas ha sido casi siempre superior al 85\% (ver gráfico 2).

La posición de los partidos valencianos de ámbito no estatal en el sistema de partidos ha sido en todo momento débil. No es necesaria una observación detallada y profunda para comprobar la enorme distancia electoral que le separa del bloque de partidos de ámbito estatal, que, generalmente, ha concentrado a más del $90 \%$ de los votos y el de los partidos de ámbito estrictamente valenciano, que sólo puntualmente consiguen más del 10\% del apoyo electoral y que se sitúan frecuentemente en cifras que rozan la marginalidad política. Con todo, hay que precisar que los resultados electorales de los PANE valencianos han oscilado considerablemente en términos relativos según el tipo de elección. Así, mientras que en las elecciones generales el apoyo tiende a descender notablemente, en las locales y autonómicas han conseguido unos resul- 


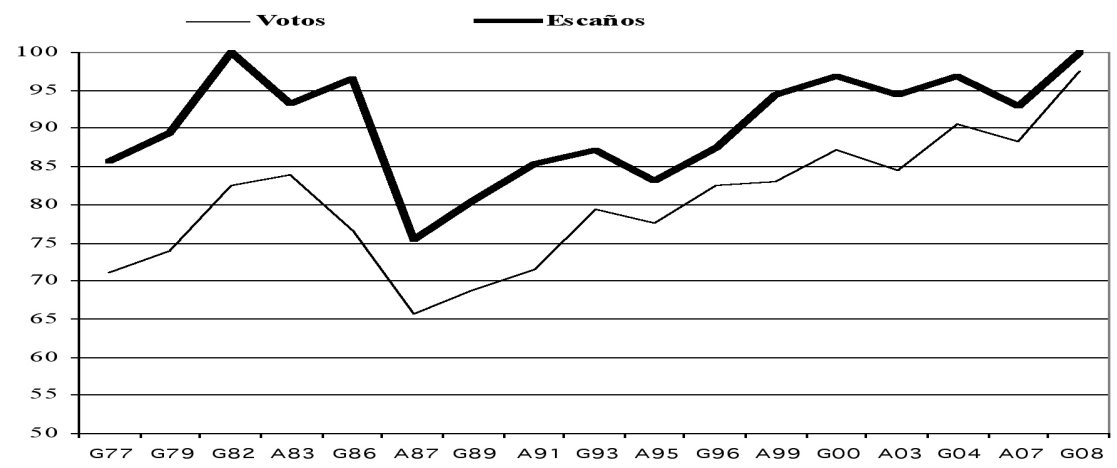

Gráfico 2. Concentración de votos y escaños en los dos partidos valencianos mayoritarios en las elecciones generales y autonómicas

Fuente: elaboración propia sobre datos de Argos. Presidencia de la Generalitat Valenciana. G (elecciones generales), A (elecciones autonómicas).

tados mejores en términos relativos. Si bien, en todo momento, las formaciones políticas de ámbito no estatal han sido minoritarias en el sistema valenciano de partidos, siendo solamente reseñables los resultados del BNV a partir de la segunda mitad de los años noventa en las elecciones locales de ciudades medias y pequeñas de la Comunidad Valenciana, y, sobre todo, la capacidad de representación política y de penetración social de Unió Valenciana desde de los años ochenta hasta finales de la década siguiente, momentos en los que, al menos en la ciudad y en la provincia de Valencia, llega a ser una fuerza política competitiva e importante en el espacio electoral conservador, e incluso llega a formar parte, como hemos visto, del Gobierno Valenciano durante una legislatura.

En términos de voto popular y de representación política, Unió Valenciana será el único partido valenciano de ámbito no estatal que consigue, como hemos dicho, durante más de una década, representación en todas las instituciones representativas: Cortes Generales, Cortes Valencianas y ayuntamientos. Así, después de romper la coalición con AP, se presentará en solitario a las elecciones generales de 1986 y locales y autonómica de 1987, y obtiene unos resultados bastante más modestos de los esperados, pero suficientes para obtener representación y presencia institucional en todos los ámbitos: el 3,1\% y un diputado nacional en las elecciones generales de 1986, el 9,16\% de los votos y 6 diputados autonómicos en 1987 y el 7,5\% de los votos y el 4\% de los concejales en las elecciones locales del mismo año (ver tabla 3 y gráfico 3 ). Estos resultados, unidos al estancamiento electoral de $\mathrm{AP}$, contribuirán a que UV crea posible llegar a ser, a medio plazo, el principal partido del centro-derecha valenciano y consolidarse de manera inmediata como la primera fuerza conservadora de la ciudad y la provincia de Valencia, donde concentraba el grueso de su electorado y tenía mayor implantación social. De hecho, como ya 


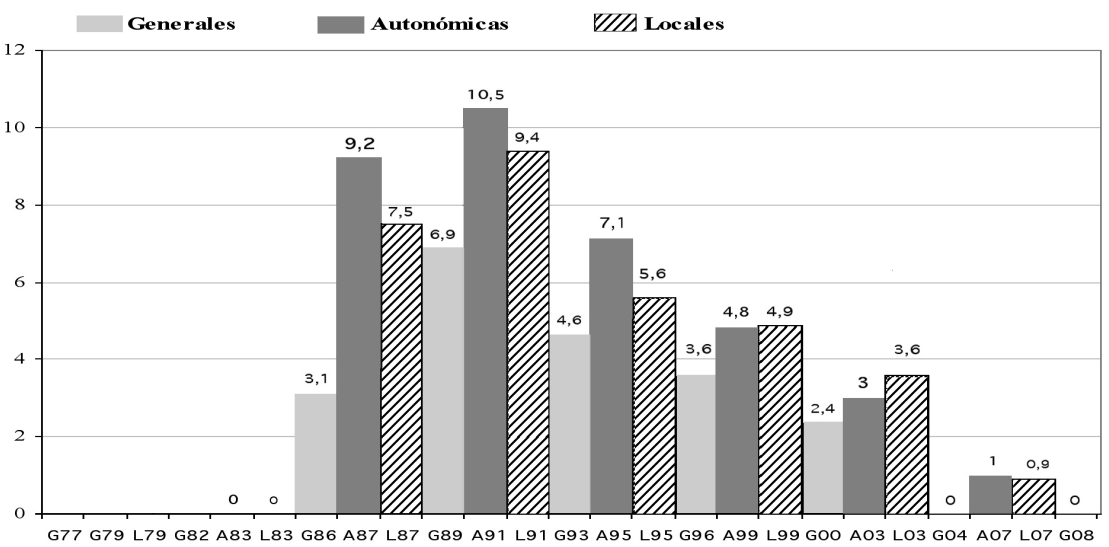

Gráfico 3. Voto a Unió Valenciana en elecciones generales, autonómicas y locales (1982-2008) Fuente: elaboración propia sobre datos del Archivo Histórico Electoral de Argos. Presidencia de la Generalitat Valenciana.

hemos visto, UV se había convertido en 1987 en la primera fuerza conservadora de la ciudad de Valencia, por delante de AP.

Pero la realidad fue que, a pesar del ligero crecimiento electoral de 1991, cuando consigue los mejores porcentajes de votos de su historia, UV queda muy lejos de estos objetivos como hemos visto; ya que, en el conjunto de la Comunidad Valenciana, el PP conseguirá el 27,69\% de los votos y UV sólo el 10,51\%. Además, estas elecciones, a pesar de que UV llegó a su nivel más alto de apoyo electoral, pusieron de manifiesto sus limitaciones para cuestionar la hegemonía del PP en la derecha valenciana a causa de su escasa implantación social y electoral fuera de la provincia de Valencia y su relativamente baja presencia institucional en los ayuntamientos, ya que, a pesar de obtener el 9,4\% del voto local, sólo consiguió un 6,28\% de los concejales, debido a que su voto se concentró tan sólo en algunas comarcas y localidades; cuestiones en las que nos detendremos inmediatamente.

Tras las elecciones de 1991, UV inicia una progresiva decadencia política, a la que no es ajena la estrategia del nuevo equipo dirigente del PP de establecer como prioridad política propia la concentración de todo el voto de centro-derecha en su partido, para poder convertirse en una alternativa estatal y autonómica al PSOE. De este modo, en las elecciones autonómicas de 1995, cuando el PP es el partido más votado en la Comunidad Valenciana, UV sufre su primer retroceso electoral significativo en términos relativos, puesto que queda con tan sólo el 7,09\% de los votos. Sin embargo, a pesar del descenso, UV será la fuerza que decidirá a favor del PP el nuevo gobierno autonómico; aunque, como hemos visto, el acceso de UV al Gobierno Valenciano, lejos de frenar su descenso electoral, lo acelerará, a causa de la división interna y del acoso del PP. Los intentos de cambiar la línea política del partido, hacerlo más 
Tabla 3. Diputados valencianos en el Congresos de los Diputados y composición de las Cortes Valencianas. Presencia de UV (1977-2008) Diputados valencianos en el Congreso de los Diputados

\begin{tabular}{|c|c|c|c|c|c|c|c|c|c|c|}
\hline & $\begin{array}{c}\text { I Leg. } \\
(1977-1979)\end{array}$ & $\begin{array}{c}\text { II Leg. } \\
(1979-1982)\end{array}$ & $\begin{array}{c}\text { III Leg. } \\
(1982-1986)\end{array}$ & $\begin{array}{c}\text { IV Leg. } \\
(1986-1989)\end{array}$ & $\begin{array}{c}\text { V Leg. } \\
(1989-1993)\end{array}$ & $\begin{array}{c}\text { VI Leg. } \\
(1993-1996)\end{array}$ & $\begin{array}{c}\text { VII Leg. } \\
(1996-2000)\end{array}$ & $\begin{array}{l}\text { VIII Leg. } \\
(2000-2004)\end{array}$ & $\begin{array}{c}\text { IX Leg. } \\
(2004-2008)\end{array}$ & $\begin{array}{l}\text { X Leg. } \\
\text { (2008-) }\end{array}$ \\
\hline PSPV-PSOE & 13 & 13 & 19 & 18 & 16 & 12 & 13 & 12 & 14 & 14 \\
\hline $\mathrm{PP}(\mathrm{AP})$ & 1 & & 10 & 10 & 9 & 15 & 15 & 19 & 17 & 19 \\
\hline EU (PCE) & 2 & 3 & & & 2 & 3 & 3 & 1 & 1 & \\
\hline UCD & 11 & 13 & & & & & & & & \\
\hline CDS & & & & 2 & 2 & & & & & \\
\hline PSP & 1 & & & & & & & & & \\
\hline CAIC & 1 & & & & & & & & & \\
\hline UV & & & & 1 & 2 & 1 & 1 & & & \\
\hline & & & & Valencia & Valencia & Valencia & Valencia & & & \\
\hline Total & 29 & 29 & 29 & 31 & 31 & 31 & 32 & 32 & 32 & 33 \\
\hline \multicolumn{11}{|c|}{ Composición de las Cortes Valencianas } \\
\hline & $\begin{array}{c}\text { I Leg. } \\
(1983-1987\end{array}$ & $\begin{array}{r}\text { II } \\
(198\end{array}$ & $\begin{array}{l}\text { I Leg. } \\
\text { 37-1991) }\end{array}$ & $\begin{array}{c}\text { III Leg. } \\
(1991-1995)\end{array}$ & \multicolumn{2}{|c|}{$\begin{array}{c}\text { IV Leg. } \\
(1995-1999)\end{array}$} & $\begin{array}{c}\text { V Leg. } \\
(1999-2003)\end{array}$ & \multicolumn{2}{|c|}{$\begin{array}{c}\text { VI Leg. } \\
(2003-2007)\end{array}$} & $\begin{array}{l}\text { VII Leg. } \\
(2007-)\end{array}$ \\
\hline PSPV-PSOE & 51 & & 42 & 45 & \multicolumn{2}{|c|}{32} & 35 & \multirow{2}{*}{\multicolumn{2}{|c|}{35}} & 38 \\
\hline $\mathrm{PP}(\mathrm{AP})$ & 32 & 25 & 31 & 42 & 49 & 48 & 54 & & & \\
\hline EU (PCE) & 6 & & $4^{*}$ & 6 & \multirow{2}{*}{\multicolumn{2}{|c|}{10}} & 5 & \multirow{2}{*}{\multicolumn{2}{|c|}{6}} & $5^{*}$ \\
\hline $\mathrm{CDS}$ & 10 & & & & & & & & & \\
\hline BNV (UPV) & \multicolumn{3}{|c|}{$2^{*}$} & \multicolumn{7}{|c|}{$2^{*}$} \\
\hline UV & \multirow{3}{*}{\multicolumn{2}{|c|}{ Valencia }} & 6 & 7 & \multirow{3}{*}{\multicolumn{2}{|c|}{5}} & & & & \\
\hline & & & alencia $6 \mathrm{Val}$ & lencia 4 & & & & & & \\
\hline & & & sstellón 1 Cast & tellón 1 & & & & & & \\
\hline Total & 89 & & 89 & 89 & \multicolumn{2}{|c|}{89} & 89 & \multicolumn{2}{|c|}{89} & $99^{* *}$ \\
\hline
\end{tabular}

Fuente: elaboración propia sobre datos del Archivo Histórico Electoral de Argos. Presidencia de la Generalitat Valenciana.

* En la II y VII legislaturas, EU y BNV forman coalición electoral.

** En la VII legislatura, el Parlamento Valenciano pasa de 89 a 99 diputados.

Leg. (legislatura). 
centrista y más nacionalista, que promovió el nuevo equipo dirigente desde 1996, no consiguieron sus objetivos. Las elecciones autonómicas de 1999 concluyeron con una derrota para UV, que obtuvo el 4,76\% de los votos y no superó, por lo tanto, la barrera autonómica del $5 \%$ de los sufragios, por lo cual quedó, por primera vez desde su fundación, sin representación en las Cortes Valencianas, y ello a pesar de aumentar ligeramente su presencia institucional municipal.

En las elecciones siguientes (generales de 2000 y locales y autonómicas de 2003), UV conoció de nuevo descensos importantes en términos relativos que mostraban la pérdida de en torno a una tercera parte de los votantes de las convocatorias inmediatamente anteriores; pero conservando, pese a todo, un número de apoyos significativos en la provincia de Valencia. Finalmente, el pacto con el PP en las elecciones generales de 2004, además de abrir nuevas crisis internas, condujo a la desaparición de ese partido de la contienda electoral y a la pérdida de la práctica totalidad de sus votantes en las elecciones locales y autonómicas de 2007, donde los resultados serán ligeramente inferiores al $1 \%$ y su presencia municipal, insignificante. En las elecciones generales de 2008, como dijimos, no se presentó a las elecciones.

Una observación rápida del origen territorial de los candidatos de UV que consiguieron acta de diputados en el Congreso de los Diputados español o en las Cortes Valencianas (ver tabla 3) nos muestra ya una presencia, una implantación y un apoyo electoral y social desigual de UV en el territorio valenciano. Desde 1986 hasta el año 2000, UV consigue representación en el Congreso de los Diputados únicamente por la provincia de Valencia, mientras que, entre 1987 y 1999, tiempo en el que forma parte de las Cortes Valencianas, la práctica totalidad de sus diputados tienen su origen en la provincia de Valencia, y tan sólo consigue uno por Castellón en dos legislaturas (1991-1999), mientras en Alicante jamás obtiene representación parlamentaria ni un apoyo electoral medianamente relevante (ver tabla 4 y 5 ).

Del mismo modo, si analizamos la representación en el ámbito municipal, comprobamos el mismo fenómeno, ya que, salvo en 2003, en que UV concurre en Alicante junto a Centro Liberal y a pequeñas escisiones locales del PP, el porcentaje de concejales o de ayuntamientos con representación de UV en la provincia había sido escasísimo (inferior al 1\% y al 5,7\%, respectivamente), mientras que en Castellón, aunque superior, el porcentaje de concejales también es muy bajo (en torno al 2\% en 1991 y en 1999), pero la presencia de algún concejal regionalista en los ayuntamientos de la provincia ha sido algo superior (entre el 8\% y el 11\% de los municipios entre 1991-2003), y siempre a bastante distancia de la provincia de Valencia, donde el porcentaje de concejales de UV se mueve entre el $7 \%$ y el $11 \%$ de 1987 a 2003 y los municipios con representación son entre el 35\% y el 42\% del total entre 1991 y 2003.

Del mismo modo, si analizamos el porcentaje de municipios en los que UV se presenta en cada provincia y las candidaturas que consiguen algún concejal, vemos que es en Valencia donde únicamente se consigue superar la presentación de candidaturas en más del 50\% de los municipios en tres elecciones 
Tabla 4. Ámbito de concejales de UV (1987-2007)

\begin{tabular}{|c|c|c|c|c|c|c|}
\hline \multicolumn{7}{|c|}{ Porcentaje de municipios con candidaturas de UV } \\
\hline $\begin{array}{l}\text { Alicante } \\
\text { Castellón } \\
\text { Valencia } \\
\text { Comunidad Valenciana }\end{array}$ & $\begin{array}{r}2,84 \\
4,44 \\
39,77 \\
21,30\end{array}$ & $\begin{array}{l}17,02 \\
14,07 \\
57,58 \\
36,11\end{array}$ & $\begin{array}{l}12,06 \\
17,78 \\
62,88 \\
38,33\end{array}$ & $\begin{array}{l}31,21 \\
22,96 \\
61,51 \\
44,07\end{array}$ & $\begin{array}{l}19,86 \\
10,37 \\
41,51 \\
28,15\end{array}$ & $\begin{array}{c}0 \\
3,70 \\
19,17 \\
10,37\end{array}$ \\
\hline & \multicolumn{5}{|c|}{ Porcentaje de municipios con concejales de UV } & 2007 \\
\hline $\begin{array}{l}\text { Alicante } \\
\text { Castellón } \\
\text { Valencia } \\
\text { Comunidad Valenciana }\end{array}$ & $\begin{array}{r}1,42 \\
2,22 \\
28,41 \\
14,81\end{array}$ & $\begin{array}{r}4,26 \\
8,15 \\
42,42 \\
23,89\end{array}$ & $\begin{array}{r}2,84 \\
8,15 \\
35,61 \\
20,19\end{array}$ & $\begin{array}{r}5,67 \\
11,11 \\
38,49 \\
23,15\end{array}$ & $\begin{array}{r}10,64 \\
4,44 \\
19,62 \\
13,52\end{array}$ & $\begin{array}{l}0 \\
1,48 \\
6,02 \\
3,33\end{array}$ \\
\hline \multicolumn{7}{|c|}{ Porcentaje de candidaturas de UV que consiguen obtener concejales } \\
\hline $\begin{array}{l}\text { Alicante } \\
\text { Castellón } \\
\text { Valencia } \\
\text { Comunidad Valenciana }\end{array}$ & $\begin{array}{l}50,00 \\
50,00 \\
71,43 \\
69,57\end{array}$ & $\begin{array}{l}25,00 \\
57,89 \\
73,68 \\
66,15\end{array}$ & $\begin{array}{l}23,53 \\
45,83 \\
56,63 \\
52,66\end{array}$ & $\begin{array}{l}18,18 \\
48,39 \\
62,58 \\
52,52\end{array}$ & $\begin{array}{l}53,57 \\
42,86 \\
47,27 \\
48,03\end{array}$ & $\begin{array}{c}- \\
40,00 \\
31,37 \\
32,14\end{array}$ \\
\hline \multicolumn{6}{|c|}{ Porcentaje de concejales de UV sobre el total de concejales valencianos } & 2007 \\
\hline $\begin{array}{l}\text { Alicante } \\
\text { Castellón } \\
\text { Valencia } \\
\text { Comunidad Valenciana }\end{array}$ & $\begin{array}{l}0,13 \\
0,37 \\
7,48 \\
4,00\end{array}$ & $\begin{array}{r}0,47 \\
2,06 \\
11,06 \\
6,28\end{array}$ & $\begin{array}{l}0,52 \\
1,51 \\
6,85 \\
4,00\end{array}$ & $\begin{array}{l}1,03 \\
2,29 \\
6,73 \\
4,23\end{array}$ & $\begin{array}{l}2,43 \\
1,24 \\
2,80 \\
2,39\end{array}$ & $\begin{array}{l}0 \\
0,37 \\
0,85 \\
0,52\end{array}$ \\
\hline
\end{tabular}

Fuente: elaboración propia sobre datos del Archivo Histórico Electoral de Argos. Presidencia de la Generalitat Valenciana. 
locales (1991, 1995 y 1999) y se trata también de la provincia en la que hay más candidaturas de UV que generan concejales, mientras que en Castellón y Alicante, además de haber un menor número de candidaturas, éstas generarán bastantes menos concejales, lo que indicaría que en estas provincias estamos ante candidaturas poco o nada representativas y que la implantación territorial del partido era muy baja fuera de una parte de la provincia de Valencia. De hecho, la mejor prueba de la limitada o insuficiente implantación de Unió Valenciana en el territorio valenciano es que la presencia de concejales de UV en municipios valencianos nunca llega a superar el 25\% de los ayuntamientos y, en muchas ocasiones, se trata de una representación minoritaria (ver tabla 4).

Pero, además de la concentración de apoyo electoral, presencia institucional e implantación social básicamente en la provincia de Valencia y en bastante menor medida en Castellón, también se observa un comportamiento electoral y una implantación política diferente en función de la dimensión sociolingüística de la Comunidad Valenciana. Así, si tenemos en cuenta las zonas históricamente valencianohablantes, que concentran en torno al $90 \%$ de la población (83\% en Alicante, 93\% en Castellón y 95\% en Valencia) y las castellanohablantes, vemos que, en las elecciones en las que ha concentrado más votantes habitualmente (elecciones a Cortes Valencianas), y la observación valdría para el resto de elecciones, UV obtiene sus mejores resultados en las comarcas históricamente valencianohablantes, sobre todo de la provincia de Valencia; mientras que, en las castellanohablantes, sus resultados son muy inferiores y prácticamente testimoniales; de hecho, sus mejores resultados (autonómicas de 1991) se fundamentan en ligeros incrementos sobre 1987 en las comarcas valencianohablantes de todas las provincias, pero sobre todo de Valencia y en menor medida de Castellón. A partir de este momento, UV empezará una progresiva regresión electoral que no seguirá una evolución igual en las distintas comarcas, ya que mejora discretamente en términos generales sus resultados en las comarcas castellanohablantes hasta llegar al 3,30\% de los votos en 2003 gracias a los pactos en la circunscripción de Alicante con pequeñas formaciones de centro-derecha escindidas del PP; mientras en las comarcas valencianohablantes se mantendrá por encima del $7 \%$ en 1995 , baja al $5,2 \%$ en 1999 (momento en que queda fuera del Parlamento valenciano) y cae al 3\% en 2003 (ver tabla 5).

Vistos los resultados electorales de UV sobre la geografía valenciana, se observa que, en las autonómicas de 1987, UV concentra la práctica totalidad de sus votos en la ciudad y las comarcas periféricas de Valencia, pierde fuerza al sur del Júcar y tiene un apoyo electoral bajo en las comarcas castellanohablantes del interior de la provincia de Valencia; mientras que en ninguna comarca de la provincia de Alicante obtiene un número de votos destacable y en Castellón sólo es reseñable el número de votos en el sur litoral valencianohablante de esta provincia. En las autonómicas de 1991, aumenta ligeramente los votos en todas las comarcas de la provincia de Valencia, sin distinción de lengua, mientras que consigue mejorar sus resultados en todas las comarcas lito- 
Tabla 5. Distribución del voto autonómico de UV por agrupación sociolingüística de comarcas (1987-2007)

\section{Porcentajes sobre voto a candidaturas}

1987

Alicante

Municipios valencianohablantes

Municipios castellanohablantes

Total

\section{1}

Municipios valencianohablantes

Municipios castellanohablantes

Total

1995

Municipios valencianohablantes

Municipios castellanohablantes

total

0,95

0,22

0,81

1,94

0,92

1,74

2,21

1,66

2,11

1999

Municipios valencianohablantes

Municipios castellanohablantes

Total

2003

Municipios valencianohablantes

Municipios castellanohablantes

Total

\section{7}

Municipios valencianohablantes

Municipios castellanohablantes

Total

Fuente: elaboración propia sobre datos del Archivo Histórico Electoral de Argos. Presidencia de la Generalitat Valenciana.

Valencia Comunidad Valenciana

3,31

1,23

3,15

15,66

3,21

10,07

15,09

1,16

9,24

$\begin{array}{rrr}5,55 & 17,08 & 11,43 \\ 1,66 & 3,23 & 1,61 \\ 5,26 & 16,44 & 10,47\end{array}$

5,55

5,26

10,47

$\begin{array}{llll}1,76 & 3,79 & 7,21 & 5,22 \\ 1,80 & 1,83 & 2,99 & 2,11 \\ 1,76 & 3,64 & 7,02 & 4,92\end{array}$

$\begin{array}{llll}1,12 & 2,18 & 4,10 & 3,00 \\ 4,58 & 0,38 & 0,79 & 3,30 \\ 1,80 & 2,06 & 3,96 & 3,03\end{array}$

$\begin{array}{llll}0,99 & 0,59 & 0,98 & 0,94 \\ 1,43 & 0,20 & 1,06 & 1,06 \\ 1,08 & 0,56 & 0,95 & 0,95\end{array}$

4,65

1,26

10,75

7,58

3,61

2,13

7,08

2,11

4,92 
rales de la provincia de Castellón y en zonas valencianohablantes del norte de la provincia de Alicante. En las elecciones autonómicas de 1995, las comarcas con mayor apoyo electoral a UV son las mismas que en 1991, pero el volumen de los votos recibidos se reduce allí donde Unión Valenciana había conseguido, en 1987 y 1991, los mejores resultados (Valencia y su área de influencia); una constante que se repite en 1999 y se generaliza a casi todas las comarcas; hasta que, en el año 2003, se llega, finalmente, a una drástica reducción de la geografía en la que UV consigue resultados de una cierta importancia, mientras que, cuatro años después, en 2007, no hay ninguna zona geográfica donde UV obtenga unos resultados mínimamente destacables.

Finalmente, habría que señalar que el regionalismo anticatalanista ha ido conformando, en las últimas décadas, un discurso político que ha justificado su actividad política y social, afirmando que, además de ser el único valencianismo auténtico y legítimo, no eran una formación política convencional, sino el producto de un movimiento espontáneo y exaltado provocado por los sentimientos de los buenos valencianos por salvar la patria valenciana de la invasión catalana y de los valencianos catalanistas ${ }^{10}$, y que, en consecuencia, estaban por encima de cualquier consideración ideológica y de la convencional distinción entre izquierda y derecha. El discurso no ha llegado a estructurarse de manera sistemática y coherente, ha sido, como hemos dicho, más emotivo que racional, más negativo que positivo, más obsesionado con el peligro catalán que con la definición de un proyecto político que afirmara qué objetivos tenía la Comunidad Valenciana políticamente como región o nación diferenciada.

Sin embargo, como hemos visto, a poco que se analice la historia y la evolución política del regionalismo anticatalanista valenciano y de UV, encontraremos que es un movimiento que, independientemente de su componente emocional y populista, y de su más que ocasional virulencia intolerante y antidemocrática, tiene poco de espontáneo políticamente hablando. Por ello no es sostenible la idea de que el anticatalanismo político, que tiene su máximo exponente en UV, sea una fuerza espontánea y transversal, un movimiento que nace por una reacción apasionada de los buenos valencianos que defienden su identidad. Políticamente, sociológicamente e ideológicamente, es un movimiento conservador vinculado desde un primer momento a la derecha tardofranquista valenciana y después a UCD y a AP y cuya vida política autónoma es paralela a la evolución de la derecha valenciana y, especialmente, a la capa-

10. En la simbología y el discurso del anticatalanismo se mitificarán personajes como Francesc de Vinatea, jurat en cap (especie de alcalde) de la ciudad de Valencia, que se enfrentó, con éxito, en 1333, al rey de la Corona de Aragón por querer pasar las principales ciudades valencianas con jurisdicción real a jurisdicción señorial; o como Vicent Doménec, el Palleter, humilde vendedor de paja para encender el fuego que, según la tradición, le declaró la guerra a Napoleón en la ciudad de Valencia en 1808. Vinatea será el símbolo de la defensa de la identidad diferenciada y la integridad del territorio y de las tradiciones valencianas. El Palleter, el de la espontaneidad de los buenos y leales valencianos que no quieren ver su tierra invadida ni quieren colaboradores de los invasores. 


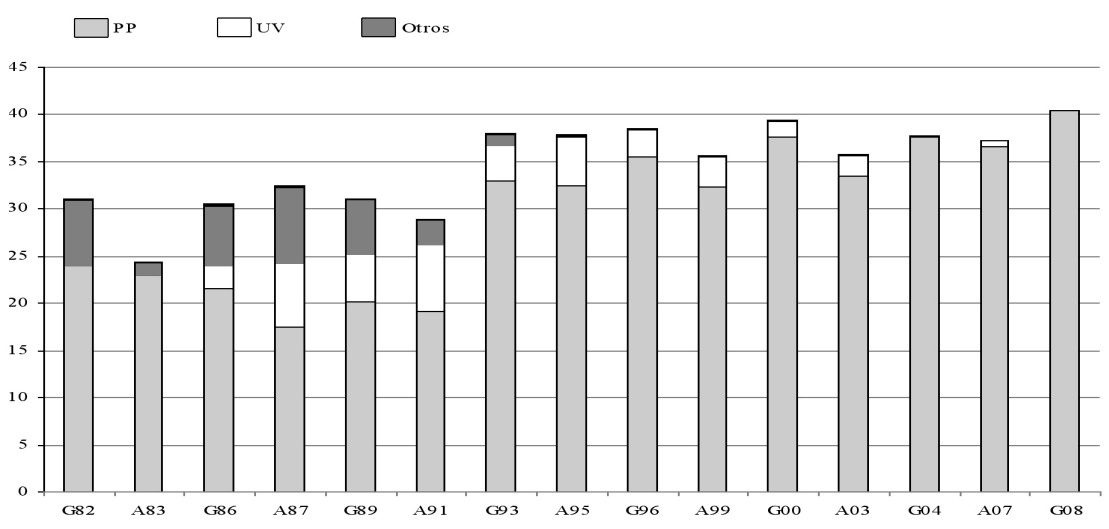

Gráfico 5. Evolución del voto sobre censo de las fuerzas de la derecha valenciana Fuente: elaboración propia sobre datos del Archivo Histórico Electoral de Argos. Presidencia de la Generalitat Valenciana.

cidad (o a las dificultades) de AP/PP para convertirse en la fuerza hegemónica de la derecha valenciana, primero, y, después, en la única significativa en términos electorales. En las primeras elecciones en que concurre Unió Valenciana, inmediatamente después de su fundación como partido (generales de 1982 y autonómicas y locales de 1983), lo hace formando parte de la Coalición Popular impulsada por AP, desde entonces, UV ha pactado habitualmente con el PP gobiernos municipales y el gobierno autonómico en 1995, $\mathrm{y}$, en su ocaso como formación de una cierta entidad, volverá a formar parte de las listas del PP valenciano en las elecciones generales de 2004.

Del mismo modo, en el PP han acabado sistemáticamente buena parte de las escisiones y los cuadros y militantes más significativos que abandonaron UV en los años noventa. Y si analizamos el voto sobre censo electoral de las fuerzas de centro-derecha, se observa una correspondencia entre el voto de UV y del PP, lo que haría pensar que la mayor parte de los antiguos votantes de UV han acabado también en el PP, como señalan los estudios postelectorales. Así, mientras en la década de los noventa, de hegemonía socialista, el voto de centro-derecha se sitúa alrededor del 30\% (salvo en las autonómicas de 1983 por la desaparición de UCD y la abstención de los votantes de esta formación en 1982); posteriormente, en las décadas de los años noventa y el 2000, en que el Partido Popular es el dominante de la política valenciana, el voto de la derecha se mueve en parámetros relativamente estables alrededor del $37,5 \%$, si bien el PP progresivamente tiene un peso mayor y concentra un porcentaje cada vez más grande del voto conservador, sin que la suma total de este voto experimente grandes variaciones, salvo en las elecciones generales de 2008, que apuntan un incremento del voto conservador valenciano a costa directamente de los socialistas (ver gráfico 5). 
Este análisis explicaría, a falta de un estudio más exhaustivo sobre la lógica y las dinámicas de los procesos de transferencia de votos e incorporación de nuevos votantes, que la evolución del voto de UV guarda una relación directa con la del PP, y que, de hecho, la integración de dirigentes, representantes institucionales, cuadros y militantes de UV en el PP a lo largo de las décadas de 1990 y 2000 ha ido acompañada también del traspaso de la mayoría de sus votantes. Además, aunque en las elecciones autonómicas de 1987, el PP apenas si concentra uno de cada dos votos de centro-derecha, UV uno de cada cinco, y la CDS el resto; cuatro años después, en el momento más álgido de UV, cuando este partido consigue uno de cada cuatro votantes de derecha, el PP ya tiene las dos terceras partes; en 2000, el PP ya concentra más del $90 \%$ del voto de derecha y a mediados de esta década, la práctica totalidad.

Pero, además, UV ha sido más un partido de la provincia de Valencia y, sobre todo, de la ciudad y del área de influencia y de las comarcas de predominio lingüístico valenciano-catalán que un partido de todo el territorio valenciano, independientemente de las provincias y las zonas lingüísticas. Como el partido que se considera el principal representante político del movimiento espontáneo de todos los buenos valencianos muestra las limitaciones geográficas, políticas e ideológicas del movimiento anticatalanista; pues, básicamente, es un partido de la ciudad y parte de la provincia de Valencia, ideológicamente no ha superado el populismo emotivo y los tópicos identitarios anticatalanistas, y, por encima de todo, ha sido una fuerza política cuya evolución ha sido paralela y ha estado en función de la historia del resto de fuerzas de la derecha valenciana desde 1982, y especialmente de AP/PP. La historia de UV y el PP tiene mucho de vidas paralelas, desde la fundación de UV en 1982 y primeros pasos con AP, hasta su crecimiento a finales de los ochenta, y su declive en los noventa, o la situación de práctica marginalidad política en la que se encuentra desde principios del 2000. De hecho, mientras UV crecía, AP/PP perdía fuerza, y cuando el PP creció, lo hizo también conquistando el espacio político, los votantes y buena parte de la militancia de UV, que, en 2008, una década después de dejar de formar parte del Gobierno Valenciano, parece haberse convertido en un partido prácticamente irrelevante en la vida política valenciana. 